\title{
加强测绘工程质量管理与控制测绘质量的有效措施
}

Effective Measures to Strengthen Quality Management and Control the Quality of

\section{Surveying and Mapping}

\section{吕相洹}

Xianghuan Lv

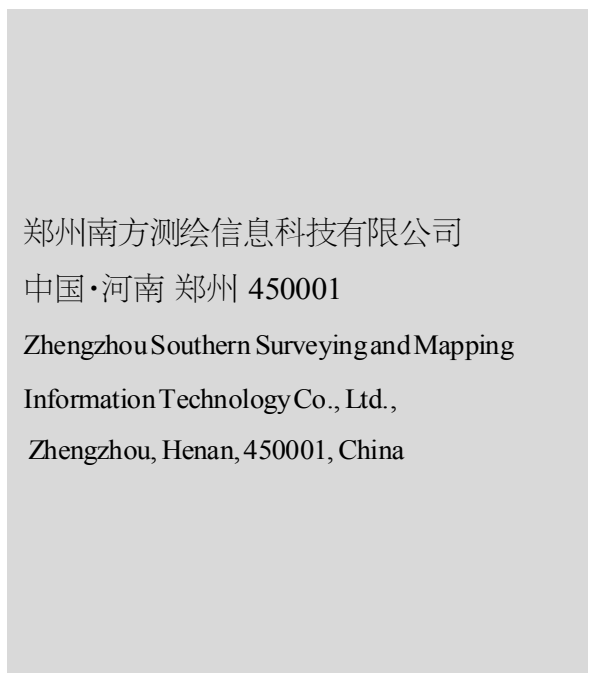

【摘要】中国经济在快速发展, 类型也越来越丰富, 关于测绘工程也就有了更加严格的 指标, 才能确保工程的质量。但该工程的发展需要专业的技术支持和严格的管理措施, 论 文对测绘工程质量管理与控制测绘质量的有效措施进行分析。

【Abstract】With the rapid development of China's economy, the types of surveying and mapping projects are becoming moreand more abundant, so that the quality of the projects can be guaranteed. However, the development of this project requires professional technical support and strict management measures. This paper analyses the effective measures of quality management and control of surveying and mapping project.

【关键词】测绘工程质量管理; 控制测绘质量; 解决措施

【Keywords 】quality management of surveying and mapping engineering; control of surveying and mapping quality; solution

【DOI】10.36012/se.v1i1.621

\section{1 引言}

测绘工程的质量决定着整个工程的质量, 为此必须严格 把关。在发展的过程中人们需要建立起系统专业的质量控制 措施, 同时, 对管理者和从业人员严格进行培养, 培养他们的 创新意识和工作的积极性。对于工程测绘质量的控制手段必 须经过多方面调节，需要各部门共同努力，才能做到协调发 展,才能加快中国的综合实力进步。

\section{2 测绘工程中存在的质量问题}

\section{1 检查工作经常出现延误}

这是整个工程的施工性质导致的，人们测绘的目标往往 是在工期全部结束以后才确定下来，这时候进行测绘工程时 一些潜在隐患便发觉得有些晚，这样往往会降低工程的整体 质量, 测绘部门的工作也会进行得十分艰难, 经常降低工期, 给工程双方带来不必要的经济损失。

\section{2 缺乏专业系统的检查措施}

工程测绘工作通常是由特定部门的固定人员进行实施 的,一开始该部门的员工们都是认真对待,但久而久之, 会不
可避免地产生倦急情绪, 测绘时得过且过, 更有员工大打感情 牌, 对于自己小组检查出来的问题, 会酌情根据人情办理。更 有甚者只检查工程的大体框架和构造, 对于其整体可能存在 的安全隐患点没有排查, 这是有非常严重后果的。这些行为都 不可取, 不仅是将自身的人身安全视若无睹, 更是缺少了基本 的从业精神, 而且遗留下来的潜在隐患也有可能造成人员伤 亡,酿成更大的错误, 这样的情况亟待解决。

\section{3 对测绘作业者的监督管理措施不到位}

由于某些工程的特殊性, 在多个位置上都要安排测绘人 员,所以经常会出现非专业人员顶替岗位的现象, 这是很正常 的。但在他们测绘完成后的质量检测工作上, 相关的专业人员 就没有上心，监督管理措施没有做到位, 一样带来了安全隐 患, 测绘工作也无法按期顺利完成。

\section{4 从业人员专业技术培训不到位, 执业水平} 下降

测绘工作是技术要求非常高的项目, 并且随着工程量的 不断增多, 技术人员也要不断地丰富自身所学, 将最新的测绘 技术及时地应用到日常的工作中, 为工程带来经济效益。与此 同时, 由于人手指派的问题, 大量的测绘人员涌人, 其质量参 
差不齐, 就更需要专业系统的技术知识培训来确保测绘工作 的顺利展开。最终培训的目的是要让每个从业者都能具有丰 富的知识储备, 以应对测绘工作中各类状况, 确保整体工程的 质量 ${ }^{[1]}$ 。

\section{3 测绘工程质量管理与控制的意义}

测绘工程质量管理与控制不仅关系到测绘工程建设的质 量与安全, 而且关系到中国经济社会发展规划的科学决策, 还 对顺利推进中国信息化建设具有十分重要的意义与作用。此 外, 测绘工程质量管理与控制是测绘单位统一管理、统一监 督、统一控制的一项重要内容, 在测绘事业发展中具有极为重 要的意义与作用。

\section{4 有效控制测绘质量的措施}

\section{1 建立和完善测绘工程质量管理机制}

测绘管理部门和测绘测绘生产单位, 要制订切实可行的 质量管理制度, 让测绘生产在制度下运行, 建立测绘质量奖惩 机制,才能保证测绘成果质量,保证测绘为国民经济建设提供 高质量的服务。

\section{2 完善管理机制}

设置合理的监督管理措施，对于测绘工作中的隐患问题 以及存在的纰漏, 需要让专业的技术人员及时地指出, 避免测 绘隐患进一步扩大给企业带来更大的损失。将测绘工作的风 险责任落实到个人, 以此调动相关从业人员的工作积极性, 也 让其在进行测绘工作时更加上心, 减少不必要的失误, 为企业 创造更高的经济效益。

\section{3 做好作业人员的综合培训}

理解了国家和企业制订的测绘操作规范后, 还要将其落
实, 大力开展培训工作, 提高从业人员的作业意识,让他们充 分意识到测绘技术的重要性。对此企业要安排好时间,规范员 工行为, 周期性地灌输指导思想, 定期组织培训, 系统地对测 绘工作人员进行知识教育, 充分了解测绘的手段和应急情况 的处理等知识，在培训后进行知识考核; 让全体人员参与其 中，要做到让他们可以在实际测绘现场从容应对突发情况， 不断强化自身的测绘知识水平, 从自身做起,做到测绘质量 控制[2]。

\section{4 设置学习标兵}

对于平时工作和培训期间表现优异的员工，要给予适当 的表扬,并且树立起模范形象,起到良好的带头作用,让企业 内部学习环境形成你超我赶的竞争趋势, 也让测绘作业的专 业知识能够更全面地渗透到员工的工作和生活中。

\section{5 结语}

测绘的质量控制发展会面临多项考验，并且往往由内部 因素和外部因素共同决定。提高从业人员素质已经是发展中 板上钉钉的事情,但合理的监督管理措施,依旧是保障其发展 的核心手段。只有从根本上内部解决发展问题,才能保证测绘 工作在各类工程中的顺利实施，无论在工程中遇到的问题多 么严峻、多么无法预料,测绘工作者都有足够的实力调整对其 进行把控。

\section{参考文献}

[1]孙䡉芳.关于测绘工程质量管理与系统控制的研究 [J].中国新 技术新产品,2015(23):133.

[2]侯志涁,加强测绘质量控制促进测绘工程发展 []].科学技术创 新,2014,5(5):68. 